Check for updates

Cite this: RSC Adv., 2017, 7, 20320

Received 13th December 2016

DOI: 10.1039/c6ra28116h

rsc.li/rsc-advances
Accepted 6th March 2017

\section{Enhanced arsenite immobilization via ternary layered double hydroxides and application to paddy soil remediation $\uparrow$}

\author{
Jizhi Zhou, (D) ab Weikang Shu, ${ }^{\text {ab }}$ Yuan Gao, ${ }^{\text {ab }}$ Zhenbang Cao, ${ }^{\text {ab }}$ Jia Zhang, ${ }^{\text {ab }}$ \\ Hao Hou, ${ }^{\mathrm{ab}}$ Jun Zhao, ${ }^{\mathrm{ab}}$ Xueping Chen, ${ }^{\mathrm{b}}$ Yun Pan ${ }^{\mathrm{ab}}$ and Guangren Qian ${ }^{\text {ab }}$
}

\begin{abstract}
A ternary $\mathrm{CaMgFe}-\mathrm{LDH}$ was developed for the immobilization of aqueous arsenic from capillary water in paddy soils, with an outstanding removal performance for aqueous arsenite (As(III)). In an As(III) solution, the ternary LDH achieved a removal capacity for arsenite of approximately $16 \mathrm{mg} \mathrm{g}^{-1}$ after $5 \mathrm{~h}$, with a low equilibrium concentration of As(III) $\left(0.048 \mathrm{mg} \mathrm{L}^{-1}\right)$. The As(III) removal capacity of LDH was studied with the different $\mathrm{Ca} / \mathrm{Mg}$ molar ratios in $\mathrm{LDH}$, which demonstrated that ternary LDHs with a higher $\mathrm{Ca}$ content can remove As(III) more effectively and rapidly. Accordingly, the ternary LDH material was used in the immobilization of total arsenic from a paddy soil system, achieving a removal efficiency for As(III) of $47 \%$ and a total As concentration of $346 \mu \mathrm{g} \mathrm{L}^{-1}$ in capillary water after 40 days. Compared to that of the binary $\mathrm{Mg}-\mathrm{Fe} \mathrm{LDH}$, the As removal performance of the ternary LDH was higher, which was attributed to the As precipitation with $\mathrm{Ca}$ in the first 20 days during the experiment. This, along with the efficient adsorption of As on the residual Mg-Fe-LDH framework, was responsible for the low concentration of As. Therefore, our study proposes a promising approach to the remediation of arsenic-contaminated paddy soils.
\end{abstract}

\section{Introduction}

Arsenic in soil poses a severe problem in several countries, such as China, Vietnam, Bangladesh, Thailand and Pakistan. Arsenic in paddy soils can be transported via capillary water of soils to rice, thus posing a high risk to human health. ${ }^{\mathbf{1 , 2}}$ Thus, a lower concentration of As in capillary water would lead to a decrease in the uptake of As by rice plants. For practical applications, sequestration by adsorption has emerged as a promising technology to remove aqueous arsenic from soil as it does not yield by-products. ${ }^{3,4}$ As a result, the adsorbents such as zeolites, ${ }^{5}$ activated alumina, ${ }^{6}$ activated carbon, ${ }^{7}$ anionic clays,${ }^{8}$ and metal oxides/hydroxides ${ }^{9}$ have been developed to remediate arseniccontaminated soils. Particularly, Fe-containing compounds, with higher affinity for selected oxyanions, have been widely used for the removal of contaminants, particularly arsenate $(\operatorname{As}(\mathrm{v})) \cdot{ }^{10,11}$ However, in paddy fields, the anaerobic medium can promote the reduction of As(v) to As(III), which is more toxic than $\mathrm{As}(\mathrm{v}) .{ }^{12,13}$ In such a case, Fe-containing compounds such as $\mathrm{Fe}_{2} \mathrm{O}_{3}$ showed a lower adsorption capacity for $\mathrm{As}(\mathrm{III})$ than for

${ }^{a}$ Center for Green Urban Mining \& Industrial Ecology, Shanghai University, No. 99 Shangda Road, Shanghai 200444, P. R. China.E-mail: grqian@shu.edu.cn

${ }^{b}$ School of Environmental and Chemical Engineering, Shanghai University, No. 99 Shangda Road, Shanghai 200444, P. R. China

† Electronic supplementary information (ESI) available. See DOI: $10.1039 / \mathrm{c} 6 \mathrm{ra} 28116 \mathrm{~h}$
As(v), which led to higher As(III) concentrations in capillary water, with further accumulation of As(III) in rice. Therefore, the efficient immobilization of arsenite is challenging. ${ }^{\mathbf{1 4}}$

The adsorption of anions on layered double hydroxides (LDHs) has attracted much attention. The general formula for LDHs is $\left[\mathrm{M}^{2+}{ }_{1-x} \mathrm{M}^{3+}{ }_{x}(\mathrm{OH})_{2}\right]^{x+}\left[\left(\mathrm{A}^{n-}\right)_{x / n} \cdot y \mathrm{H}_{2} \mathrm{O}\right]^{x-}$, where $\mathrm{M}^{2+}$ and $\mathrm{M}^{3+}$ represent divalent and trivalent metal cations, respectively, and $x$ denotes the molar ratio of $\mathrm{M}^{3+}$ to total metal, which ranges from 0.23 to 0.30 for a pure $\mathrm{LDH}$ structure. ${ }^{15} \mathrm{~A}^{n-}$ represents the interlayer anions, which balance the positive charge on the metal hydroxide layer. As the bonding interactions between layers and anions are relatively weak, host anions such as $\mathrm{NO}^{3-}$ and $\mathrm{Cl}^{-}$in LDHs can be readily exchanged with various guest organic and inorganic anions. Based on this feature, LDHs have already been proven more efficient for the removal of various oxyanions, including phosphate, chromate, selenite and arsenate, than Fe oxides or hydroxides. ${ }^{16-18}$ Since As(III) shares a similar microstructure with the abovementioned oxyanions, LDHs could be potential candidates for As(III) immobilization.

In addition to anion exchange, the variety of cations contained in the LDH layer also improved the capture of anions. In our previous study, a Ca-based $\mathrm{LDH}$ was used to remove arsenic from an aqueous solution by precipitation of calcium arsenate. ${ }^{18}$ In another study, Ca was doped into a MgFe-LDH to form a ternary $\mathrm{MgCaFe}-\mathrm{LDH}$ for the enhanced removal of pyrophosphate (PP) and triphosphate (TPP) in water. The results 
demonstrated that the release of $\mathrm{Ca}$ from the $\mathrm{LDH}$ matrix was responsible for the precipitation of anions, while anion exchange on the resultant Mg-rich LDH framework contributed to the immobilization of anions. ${ }^{17,19}$ Since the precipitation of As(III) with Ca was also verified in solution, ${ }^{\mathbf{2 0 , 2 1}}$ it was suggested that As(III) may be immobilized more effectively by the $\mathrm{Ca} / \mathrm{Mg}$ ternary LDH than by the binary system from both capillary water and soil. To the best of our knowledge, the application of ternary LDH systems for As(III) immobilization from paddy soils has not been reported.

Therefore, the objectives of this study were the following: (1) to prepare and characterize a series of LDHs with different $\mathrm{Mg}$ / Ca ratios; (2) to study the removal of As(III) by the as-prepared LDHs based on the isotherm and kinetics curves; and (3) to establish an efficient process for the removal of As by the assynthesized LDH from a simulated paddy field system.

\section{Materials \& methods}

\subsection{Synthetic procedures}

All chemicals were purchased from Sinopharm Chemical Reagent Co., Ltd., China. All reagents were of analytical grade and were used as received without further purification. To minimize contamination with carbon dioxide, deionized water was used in the experiments. The corresponding $\mathrm{Mg}_{3-x} \mathrm{Ca}_{x} \mathrm{Fe}-$ Cl-LDHs samples, where $x=0,0.3,1.0,1.5$ and 3.0, were denoted as $\mathrm{LDH}_{x}$. These were prepared via coprecipitation by addition of the pre-mixed metal chlorides to a basic solution under vigorous stirring. For instance, to prepare $\mathrm{LDH}_{3}, 8.820 \mathrm{~g}$ of $\mathrm{CaCl}_{2} \cdot 2 \mathrm{H}_{2} \mathrm{O}(0.06 \mathrm{~mol})$ and $6.762 \mathrm{~g}$ of $\mathrm{FeCl}_{3} \cdot 10 \mathrm{H}_{2} \mathrm{O}(0.02 \mathrm{~mol})$ were dissolved in $50 \mathrm{~mL}$ of water (solution A). Solution B was prepared by dissolving $6.0 \mathrm{~g}(0.150 \mathrm{~mol})$ of $\mathrm{NaOH}$ in $100 \mathrm{~mL}$ of water. Solution A was added to solution B under vigorous stirring for $4 \mathrm{~h}$ and subsequently, the suspension was aged for $18 \mathrm{~h}$ at room temperature in a $\mathrm{N}_{2}$ atmosphere. The precipitate was collected by centrifugation at $2500 \mathrm{rpm}$ for $8 \mathrm{~min}$ and washed twice with $150 \mathrm{~mL}$ of deionized water. Sample was desiccated at $60{ }^{\circ} \mathrm{C}$ in a vacuum oven. Other LDHs were prepared in the similar way by varying $x$ according to the designed value.

\subsection{Removal of aqueous As(III)}

For the adsorption isotherms, a series of As(III) solutions with concentrations ranging from 1 to $12 \mathrm{mg} \mathrm{L}^{-1}$ at a $\mathrm{pH}$ of 7.0 were prepared by dissolving $\mathrm{Na}_{3} \mathrm{AsO}_{3}$. Typically, $1000 \mathrm{~mL}$ of the As(III) solution and $0.50 \mathrm{~g}$ of $\mathrm{LDH}_{x}$ were mixed in a sealed conical flask. The adsorption was conducted under oscillation in a water bath at $25{ }^{\circ} \mathrm{C}$ and the remaining arsenite(III) concentration in each solution was determined accordingly within $24 \mathrm{~h}$. The kinetics for the removal of $\mathrm{As}(\mathrm{III})$ by $\mathrm{Mg}_{3-x} \mathrm{Ca}_{x} \mathrm{FeCl}-\mathrm{LDHs}$ was investigated by monitoring the As(III) concentration in $1000 \mathrm{~mL}$ of a solution with an initial As(III) concentration of $10 \mathrm{mg} \mathrm{L}^{-1}$ to which $0.50 \mathrm{~g}$ of $\mathrm{LDH}_{x}$ had been added. At certain intervals, $5 \mathrm{~mL}$ of solution were extracted, and filtered through a $0.22 \mu \mathrm{m}$ microporous membrane prior to determining As(III) concentration. Other metal concentrations were also analyzed.

\subsection{Release of As(III) in a paddy field system and removal by LDH}

Five duplicated samples of $450 \mathrm{~g}$ of paddy soil were artificially contaminated by adding $0.48 \mathrm{mmol}$ of $\mathrm{As}(\mathrm{III})$. One of the duplicates was set as a control group, while $\mathrm{LDH}_{1}$ and $\mathrm{LDH}_{0}$ were added in other four duplicates. Soil samples were aged for 30 days after contamination with $\mathrm{As}(\mathrm{III})$ to ensure a better immobilization of As(III).

Three circular plastic buckets $(1 \mathrm{~L}$, diameter $10 \mathrm{~cm}$ ) were weighed, and the soil was added into these buckets. Rhizon sampler pipes for capillary water were placed into the soil. The water was gently added to the buckets until the height of surface water was $3 \mathrm{~cm}$ over soil. The buckets were maintained at a constant temperature $\left(25^{\circ} \mathrm{C}\right)$ and humidity $(55 \% \mathrm{RH})$. From the flanks of the buckets, $5 \mathrm{~mL}$ of capillary water were sampled every day via vacuum tubes, and the $\mathrm{pH}$ of the water sample was measured. All samples were acidified with $0.6 \mathrm{mmol}$ of $\mathrm{HCl}$, and then stored at $4{ }^{\circ} \mathrm{C}$. Then, the concentration of metal ions and As(III) was measured. The LDH dosage of 0.2 and $2.0 \mathrm{~g}$ was used at the equilibrium of As(III) removal.

\subsection{Characterization}

A portable $\mathrm{pH}$-meter with a glass electrode (Aqua Cond/pH, TPS) was used to measure the $\mathrm{pH}$. The concentration of heavy metals in solution was analysed by inductively coupled plasma-atomic emission spectrometry (ICP-AES, Prodigy, Leeman Co.). After centrifugation and filtration with a $0.22 \mu \mathrm{m}$ filter, the concentration of As(III) and As(v) was determined by high performance liquid chromatography-hydride generation-atomic absorption spectroscopy (HPLC-HG-AAS). These species were separated with a Hamilton PRP-100. The total concentration of As was determined by the same method but without using a Hamilton PRP-100. The powder X-ray diffraction patterns for the solid sample were recorded on a Dmax/RB diffractometer (Rigaku Co.) with $\mathrm{Cu} \mathrm{K} \alpha$ radiation $(\lambda=0.15406 \mathrm{~nm})$ at $40 \mathrm{kV}$ and $100 \mathrm{~mA}$. Crystalline parameters were calculated by the Scherrer equation. The Powder Data File (ICDD-JCPDS) was used for the analysis of the patterns. The C content of the LDHs was determined by elemental analysis (EA3000, Leeman Co.).

\section{Results and discussion}

\subsection{Characterization of solid samples before and after As(III)} removal

Fig. 1A shows the XRD patterns of the as-synthesized LDHs with various $\mathrm{Ca}$ contents. The XRD pattern of the $\mathrm{Mg}$-based binary $\mathrm{LDH}\left(\mathrm{LDH}_{0}\right)$ displayed a series of diffraction peaks at $11.14^{\circ}$, $22.44^{\circ}, 34.32^{\circ}, 59.34^{\circ}$ and $60.90^{\circ}$. The XRD pattern of $\mathrm{LDH}_{3}$ displayed diffraction peaks at $11.31^{\circ}, 23.14^{\circ}, 38.39^{\circ}, 54.12^{\circ}$ and $55.90^{\circ}$, which were indexed to the Ca-based binary LDH. In the XRD of ternary $\operatorname{LDH}_{x}(x=0.3,1.0,1.5)$, characteristic peaks of both $\mathrm{Mg}$-LDH and Ca-LDH were observed as the Ca content increased in Mg-based LDHs. No impurity was observed in any of the samples, suggesting that pure LDH was synthesized as expected. The lattice parameters obtained from the XRD patterns are listed in Table 1. According to the Bragg's law for 

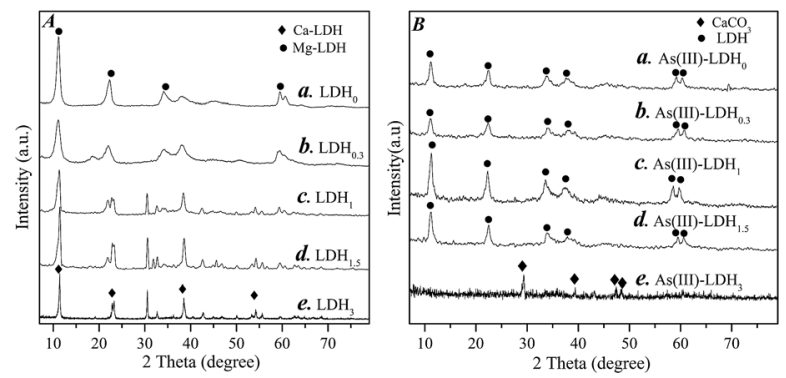

Fig. 1 (A) XRD patterns of the synthetic LDHs, (B) XRD patterns of the $\mathrm{LDH}$ sample after As(III) removal; (a) $\mathrm{LDH}_{0}$, (b) $\mathrm{LDH}_{0.3}$, (c) $\mathrm{LDH}_{1}$, (d) $\mathrm{LDH}_{1.5}$ and (e) $\mathrm{LDH}_{3}$.

the crystalline, the $d$-spacing indicated the formation of a layered structure, and the intercalation of Ca within the layers led to a decrease of the interlayer distance. This indicated the successful establishment of a ternary LDH system. The results of the elemental analysis are also listed in Table 1. The metal composition was close to the designed value for most samples. The ratio of divalent to trivalent metal ranged from 2.26-2.9, which was within the value for pure $\mathrm{LDH}$, in agreement with the XRD results. The Ca content in $\mathrm{LDH}_{0.3}$ was not as high as expected, indicating that its structure was closer to that of the binary $\mathrm{Mg}$-LDH. Interestingly, despite the significant variation on the determined $\mathrm{Mg} / \mathrm{Ca}$ molar ratio in $\mathrm{LDH}_{1}$ and $\mathrm{LDH}_{1.5}$ (ranged from 1.23 to 2.63), both samples demonstrated an identifiable ternary LDH structure. Due to the release of Ca from the LDHs, it was assumed that both $\mathrm{LDH}_{1}$ and $\mathrm{LDH}_{1.5}$ were able to remove As(III) by precipitation with the released $\mathrm{Ca}$, as well as by adsorption on the LDH matrix. Moreover, with the increase in $\mathrm{Ca}$ content, the carbon content in the LDHs increased slightly, which suggested a higher number of carbonate anions in the interlayer of ternary LDHs. In addition, the $\operatorname{LDH}_{x}(x=$ 0.3-1.5) formula was estimated, which indicated the proportion of $\mathrm{Cl}$ in ternary LDHs was higher than that in the binary CaLDH. Such result suggested a higher anion-exchange ability for the ternary LDHs.

Fig. $1 \mathrm{~B}$ shows the XRD diffraction patterns of the LDH samples after As(III) removal. On the pattern of the resultant $\mathrm{LDH}_{3}$ there were no LDH characteristic peaks, and only those attributed to $\mathrm{CaCO}_{3}$ were observed, which indicated the collapse of the LDH structure upon Ca release. On the other hand, the XRD pattern of $\mathrm{LDH}_{0}$ displayed diffraction peaks at $11.31^{\circ}, 22.48^{\circ}, 33.79^{\circ}, 37.63^{\circ}, 59.02^{\circ}$ and $60.36^{\circ}$, which were indexed to $\mathrm{Mg}-\mathrm{LDH}$. This suggested the adsorption of As(III) on the binary Mg-LDH. For ternary LDH samples, the diffraction peaks of Mg-LDH could be observed while no diffraction peaks of Ca-LDH were observed regardless of Ca content before As(III) removal (such as $\mathrm{LDH}_{1}$ and $\mathrm{LDH}_{1.5}$ ). The $d$-spacing value of $\mathrm{LDH}$ strucutre in XRD patterns of $\mathrm{LDH}_{0}, \mathrm{LDH}_{0.3}, \mathrm{LDH}_{1}$ and $\mathrm{LDH}_{1.5}$ after $\mathrm{As}(\mathrm{III})$ adsorption was $0.7925,0.8010,0.7928$ and $0.7929 \mathrm{~nm}$, respectively, close to that of $\mathrm{LDH}_{0}$ before adsorption of As(III). These results were consistent with our previous work on phosphate removal by ternary LDHs and suggested that the Mg-LDH framework in solution was highly stable. ${ }^{17}$ Accordingly, As(III) removal can occur both via adsorption on the LDH structure and via precipitation with the Ca released from the ternary LDHs.

\subsection{Performance of ternary LDHs for the removal of aqueous As(III)}

Fig. 2 shows the kinetics and isotherm curves for the removal of aqueous As(III) by LDHs with different contents of Ca. As shown in Fig. $2 \mathrm{~A}$, the kinetics of $\mathrm{As}(\mathrm{III})$ removal by $\mathrm{LDH}_{0}$ over $24 \mathrm{~h}$ involved a relatively sharper increase in the amount removed within the first $10 \mathrm{~h}$, followed by a gentle increase thereafter. The maximum removal capacity was approximately $15 \mathrm{mg} \mathrm{g}^{-1}$, indicating that $75 \%$ of As(III) was removed. In comparison, LDHs containing Ca exhibited a higher removal capacity for As(III). A rapid increase in the amount of As(III) removed was observed for $\mathrm{LDH}_{x}(x=0.3,1,1.5)$ in the first $2-7 \mathrm{~h}$, with a constant removal capacity of $15 \mathrm{mg} \mathrm{g}^{-1}$ at equilibrium. Thus, a higher content of $\mathrm{Ca}$ in the LDHs appeared to favour a rapid equilibrium. For instance, $\mathrm{LDH}_{1.5}$ reached equilibrium for As(III) removal after $2 \mathrm{~h}$, while $\mathrm{LDH}_{0.3}$ reached equilibrium after $7 \mathrm{~h}$. Table 2 lists the results obtained after fitting the kinetics data to a Laguerre first-order equation and simplified Elovich equation, which indicated that the removal kinetics was in better accordance with a Laguerre first-order equation. It also suggested that the removal of As(III) could be described by a chemical reaction equation. Moreover, the reaction rate constant $\left(K_{1}\right)$ increased as the estimated removal capacity $\left(q_{\mathrm{e}}\right)$ at equilibrium increased. $\mathrm{LDH}_{1.5}$ exhibited the maximum removal capacity, of $15.6 \mathrm{mg} \mathrm{g}^{-1}$, which was higher than that of $\mathrm{LDH}_{0}$.

Table 1 Lattice parameters and chemical composition of $\mathrm{Mg}_{3-x} \mathrm{Ca}_{x} \mathrm{FeCl}-\mathrm{LDH}$

\begin{tabular}{llllll}
\hline & & & \multicolumn{2}{c}{ Measured composition ${ }^{b}$} & \\
Samples & Carbon content (\%) & $d$-Spacing ${ }^{a}(\mathrm{~nm})$ & $\mathrm{Mg} / \mathrm{Ca}$ & $\mathrm{M}(\mathrm{II}) / \mathrm{Fe}(\mathrm{III})$ & Estimated LDH formula $^{c}$ \\
\hline $\mathrm{LDH}_{3}$ & 3.03 & 0.763 & - & 2.87 & $\mathrm{Ca}_{2.9} \mathrm{FeCl}_{0.52}\left(\mathrm{CO}_{3}\right)_{0.24} \cdot 4.9 \mathrm{H}_{2} \mathrm{O}$ \\
$\mathrm{LDH}_{1.5}$ & 2.26 & 0.773 & 1.23 & 2.60 & $\mathrm{Mg}_{1.4} \mathrm{Ca}_{1.2} \mathrm{FeCl}_{0.70}\left(\mathrm{CO}_{3}\right)_{0.15} \cdot 3.2 \mathrm{H}_{2} \mathrm{O}$ \\
$\mathrm{LDH}_{1}$ & 0.99 & 0.781 & 2.63 & 2.83 & $\mathrm{Mg}_{2.0} \mathrm{Ca}_{0.8} \mathrm{FeCl}_{0.86}\left(\mathrm{CO}_{3}\right)_{0.068} \cdot 2.8 \mathrm{H}_{2} \mathrm{O}$ \\
$\mathrm{LDH}_{0.3}$ & 0.63 & 0.795 & 20.7 & 2.26 & $\mathrm{Mg}_{2.2} \mathrm{Ca}_{0.1} \mathrm{FeCl}_{0.93}\left(\mathrm{CO}_{3}\right)_{0.037} \cdot 2.1 \mathrm{H}_{2} \mathrm{O}$ \\
$\mathrm{LDH}_{0}$ & 0.37 & 0.804 & - & 2.90 & $\mathrm{Mg}_{2.9} \mathrm{FeCl}_{0.95}\left(\mathrm{CO}_{3}\right)_{0.024} \cdot 2 \mathrm{H}_{2} \mathrm{O}$
\end{tabular}

${ }^{a} d$-Spacing was calculated by the equation $d$-spacing $=\left(d_{003}+2 d_{006}\right) / 2 .{ }^{b}$ M represents a divalent metal, either Mg, Ca or both. ${ }^{c}$ Compositions were determined by the stoichiometric number of Fe. 

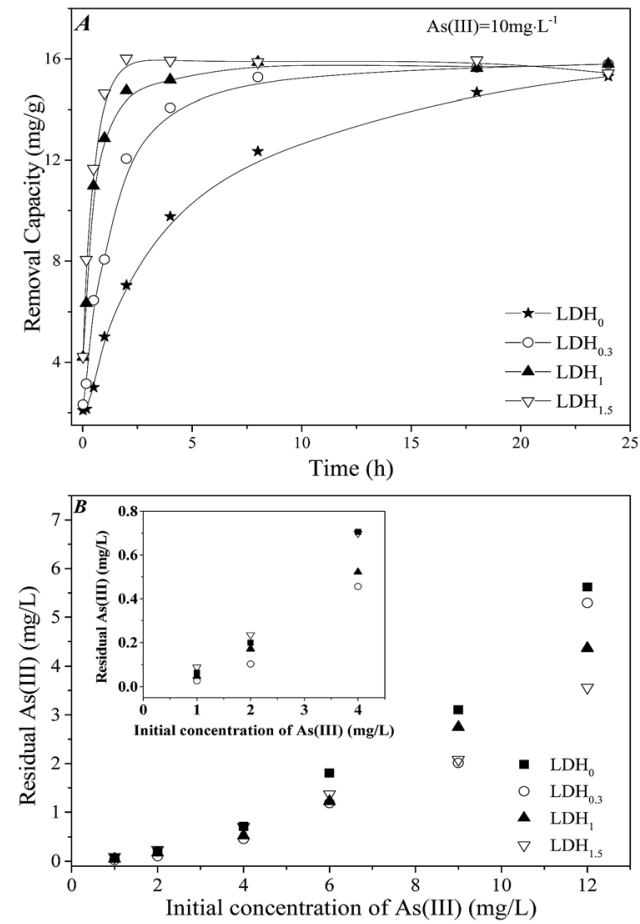

Fig. 2 Study of the removal of As(III) by LDHs: (a) removal kinetics for a As(III) concentration of $10 \mathrm{mg} \mathrm{L}^{-1}$ and (b) adsorption isotherms for As(III) concentrations ranging from 1-12 $\mathrm{mg} \mathrm{L}^{-1}$.

Table 2 Parameters of kinetic modeling of As(III) removal by $\mathrm{Mg}_{3-x^{-}}$ $\mathrm{Ca}_{x} \mathrm{FeCl}-\mathrm{LDH}$ for $C_{0}=10 \mathrm{mg} \mathrm{L}^{-1}\left(C_{0}\right.$ denotes the initial concentration of $\mathrm{As}($ III))

\begin{tabular}{|c|c|c|c|c|c|c|}
\hline \multirow[b]{2}{*}{ Samples } & \multicolumn{3}{|c|}{$\begin{array}{l}\text { First order Lagergren } \\
\text { equation } q_{t}=q_{\mathrm{e}}(1- \\
\left.\exp \left(-K_{1} t\right)\right)\end{array}$} & \multicolumn{3}{|c|}{$\begin{array}{l}\text { Simplified Elovich equation } \\
q_{t}=A+B \ln t\end{array}$} \\
\hline & $K_{1}$ & $q_{\mathrm{e}}$ & $R^{2}$ & $A$ & B & $R^{2}$ \\
\hline $\mathrm{LDH}_{0}$ & 0.0054 & 14.5140 & 0.9484 & -1.4165 & 2.0779 & 0.8299 \\
\hline $\mathrm{LDH}_{0.3}$ & 0.0143 & 15.2834 & 0.9582 & 0.3474 & 2.2160 & 0.9087 \\
\hline $\mathrm{LDH}_{1}$ & 0.0454 & 15.2380 & 0.8793 & 4.4352 & 1.7709 & 0.8900 \\
\hline $\mathrm{LDH}_{1.5}$ & 0.0616 & 15.6000 & 0.8858 & 5.5665 & 1.6711 & 0.8194 \\
\hline
\end{tabular}

Thus, the improvement in the As(III) removal capacity by the incorporation of Ca suggested that the As(III) removal capacity of MgFe-LDH could be enhanced by adding Ca to the LDH structure. This was in agreement with the results obtained for the adsorption of phosphate on $\mathrm{MgCaFe}-\mathrm{LDH}$ on a previous work. ${ }^{17}$

The As(III) removal capacity of $\mathrm{LDH}_{x}(0.3<x<1.5)$ was evaluated for various initial concentrations of $\operatorname{As}\left(\right.$ III) $\left([\operatorname{As}(\text { III) })]_{\text {ini }}\right)$, and compared to that of $\mathrm{LDH}_{0}$. As shown in Fig. 2B, the equilibrium concentration of $\operatorname{As}(\mathrm{III})$ after its removal $\left([\mathrm{As}(\mathrm{III})]_{\mathrm{fin}}\right)$ on all samples was higher for higher $[\operatorname{As}(\mathrm{III})]_{\mathrm{ini}}$. For instance, for $\mathrm{LDH}_{1.5}$, the $[\mathrm{As}(\mathrm{III})]_{\text {fin }}$ increased from $0.089 \mathrm{mg} \mathrm{L}^{-1}$ to $3.56 \mathrm{mg}$ $\mathrm{L}^{-1}$ as $[\operatorname{As}(\mathrm{III})]_{\mathrm{fin}}$ increased from $1 \mathrm{mg} \mathrm{L}^{-1}$ to $12 \mathrm{mg} \mathrm{L}^{-1}$. Likewise, the $[\operatorname{As}(\mathrm{III})]_{\mathrm{fin}}$ for $\mathrm{LDH}_{0}$ at the highest $[\operatorname{As}(\mathrm{III})]_{\mathrm{ini}}$ was $5.62 \mathrm{mg} \mathrm{L}^{-1}$, with a $[\operatorname{As}(\mathrm{III})]_{\text {in }}$ of $0.065 \mathrm{mg} \mathrm{L}^{-1}$ at a $[\operatorname{As}(\mathrm{III})]_{\mathrm{ini}}$ of $1 \mathrm{mg} \mathrm{L}^{-1}$. The same trend was observed for $\mathrm{LDH}_{0.3}$. It should be noted that the $[\operatorname{As}(\mathrm{III})]_{\mathrm{fin}}$ for a high $[\mathrm{As}(\mathrm{III})]_{\text {ini }}$ depended on the Ca content in the
LDHs. As a result, the maximum removal capacity for As(III) decreased from $17.2 \mathrm{mg} \mathrm{g}^{-1}$ to $13.1 \mathrm{mg} \mathrm{g}^{-1}$ as the $x$ value decreased from 1.5 to 0 . Therefore, it was concluded that the ternary LDHs with $x=1.0$ and 1.5 displayed excellent removal performances, especially for As(III) contamination at relatively high concentrations.

On the other hand, the immobilization of As(III) at low concentrations from soil capillary water is also of much interest. As discussed above, for a $[\operatorname{As}(\mathrm{IIII})]_{\text {ini }}$ of $1 \mathrm{mg} \mathrm{L}^{-1}$, the $[\operatorname{As}(\mathrm{III})]_{\mathrm{fin}}$ for $\mathrm{LDH}_{0}$ was lower than for $\mathrm{LDH}_{1.5}$. This suggested that the adsorption on the LDH led to the improvement of As(III) immobilization at low As(III) concentrations. Interestingly, the $[\operatorname{As}(\mathrm{III})]_{\mathrm{fin}}$ for $\mathrm{LDH}_{0.3}$ and $\mathrm{LDH}_{1.0}$ was 0.027 and $0.048 \mathrm{mg} \mathrm{L}^{-1}$, respectively, lower than that for $\mathrm{LDH}_{0}$. This indicated that a small portion of Ca in LDH $(x=0.3$ and 1.0) was probably responsible for As(III) immobilization at low $[\mathrm{As}(\mathrm{III})]_{\text {ini. }}$. Consequently, controlling Ca content in the LDH appears to be key for As(III) immobilization. For further investigation of the As(III) removal process, $\mathrm{LDH}_{1.0}$ was selected as a model sample due to its relatively high performance in the removal of As(III) among all the $\mathrm{LDH}_{x}(0.3<x<1.5)$.

\subsection{LDH composition after removal}

As expected, the leaching of $\mathrm{Mg}$ or $\mathrm{Ca}$ correspondingly changed the final $\mathrm{pH}$ when LDHs were used for anion removal. ${ }^{18,22}$ In terms of the solubility of the individual hydroxides, $\mathrm{Ca}(\mathrm{OH})_{2}$ $\left(K_{\mathrm{sp}}=5.02 \times 10^{-6}\right)$ is much more soluble than $\mathrm{Mg}(\mathrm{OH})_{2}\left(K_{\mathrm{sp}}=\right.$ $\left.5.61 \times 10^{-12}\right)$, and $\mathrm{Fe}(\mathrm{OH})_{3}$ is almost insoluble at $\mathrm{pH}=8-11$ $\left(K_{\mathrm{sp}}=2.79 \times 10^{-39}\right) .{ }^{23}$ In the LDHs, the solubility of LDH was dependent on the dissolution of corresponding hydroxides in solution. Therefore, most $\mathrm{Ca}$ was dissolved in the solution, increasing water $\mathrm{pH}$. In contrast, only a small fraction of $\mathrm{Mg}$ dissolved, lowering $\mathrm{pH} .{ }^{18}$ In addition, the leaching of divalent metals $(\mathrm{Mg}$ and $\mathrm{Ca}$ ) leaves a Fe-rich network with a higher surface area, ${ }^{22}$ which clearly improves the adsorption capacity for oxyanions.

In order to gain insight on the effect of composition in $\mathrm{LDH}_{x}$, the concentration of $\mathrm{Ca}$ and $\mathrm{Mg}$, and the $\mathrm{pH}$ during $\mathrm{As}(\mathrm{III})$ removal were determined, and results are shown in Fig. $3 . \mathrm{Mg}^{2+}$ was determined for $\mathrm{LDH}_{0}, \mathrm{LDH}_{0.3}, \mathrm{LDH}_{1}$ and $\mathrm{LDH}_{1.5}$ (Fig. 3c). $\mathrm{Mg}$ concentration remained relatively constant at $5.4-6.2 \mathrm{mg}$ $\mathrm{L}^{-1}$ and $2.7-3.5 \mathrm{mg} \mathrm{L}^{-1}$ for $\mathrm{LDH}_{0.3}$ and $\mathrm{LDH}_{0}$, respectively, despite the fact that the amount of As(III) removed was increasing. This indicated that theoretically, a $6 \%$ and $4 \%$ of $\mathrm{Mg}$ had dissolved after As(III) removal for $\mathrm{LDH}_{0.3}$ and $\mathrm{LDH}_{0}$, respectively. In contrast, no $\mathrm{Mg}$ in solution was detected for either $\mathrm{LDH}_{1}$ or $\mathrm{LDH}_{1.5}$, which suggested that LDHs with a lower amount of $\mathrm{Mg}$ had a more stable structure. Fig. 3a shows the profile for the leaching of Ca during As(III) removal, which was similar to that of $\mathrm{Mg}$. A lower amount of Ca within the ternary LDH clearly led to a lower equilibrium concentration of $\mathrm{Ca}$. The value of dissolved $\mathrm{Ca}$ for $\mathrm{LDH}_{1.5}, \mathrm{LDH}_{1}$ and $\mathrm{LDH}_{0.3}$ was approximately 60,40 and $5 \mathrm{mg} \mathrm{L}^{-1}$, suggesting that $93 \%, 95 \%$ and $82 \%$ of Ca had leached out, respectively. Visual MINTEQ was used to study the possibility of precipitation, and the results showed that no $\mathrm{Ca}$ or $\mathrm{Mg}$ hydroxides would precipitate in 

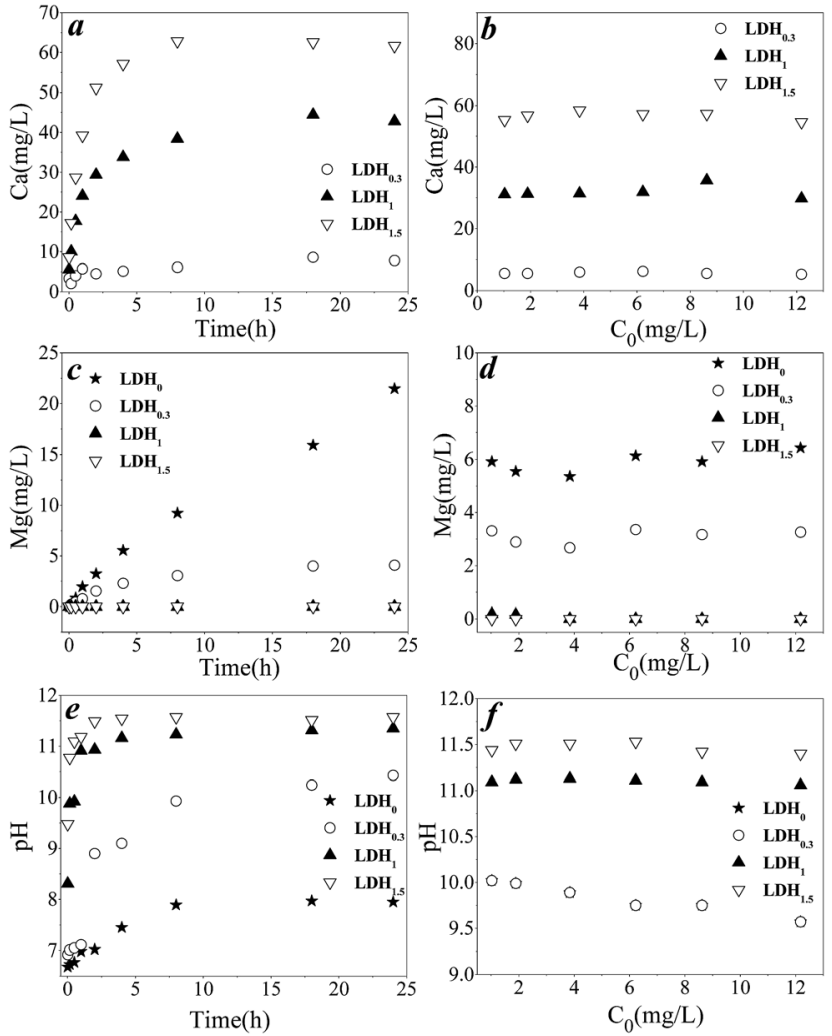

Fig. 3 Concentration of aqueous $\mathrm{Ca}$ ( $\mathrm{a}$ and $\mathrm{b}$ ) and $\mathrm{Mg}$ ( $\mathrm{c}$ and $\mathrm{d}$ ), and $\mathrm{pH}$ changes (e and f) during removal of As(III); the initial As(III) concentration in (a), (c) and (e) was $10 \mathrm{mg} \mathrm{L}^{-1}$, and the dosage of LDH was $0.5 \mathrm{~g}$ $\mathrm{L}^{-1}$ in each sample.

solution (the dominant species for $\mathrm{Ca}$ was $\mathrm{Ca}^{2+}$, and another species was $\mathrm{Ca}(\mathrm{OH})^{+}$; the same applied to $\left.\mathrm{Mg}\right)$. The detailed species distribution is shown in Table S2. $\dagger$ As equilibrium of $\mathrm{Ca}$ for $\mathrm{LDH}_{3}$ was reached rapidly with a high removal amount of As(III) (Fig. S1 $\dagger$ ), the leaching of $\mathrm{Ca}$ in $\mathrm{LDH}_{1.5}$ and $\mathrm{LDH}_{1}$ could lead to a higher As(III) removal within a short time. Since the removal of As(III) via anion exchange was a comparatively slower process (Fig. 2), the simultaneous removal of As by precipitation, which was well exhibited on $\mathrm{LDH}_{1}$, and its practical application was further investigated in the next section.

As a result of metal release, the $\mathrm{pH}$ in $\mathrm{LDH}_{0.3}$ was approximately 10 , and $\mathrm{pH}$ was close to 11 for both $\mathrm{LDH}_{1}$ and $\mathrm{LDH}_{1.5}$. Furthermore, no evident $\mathrm{pH}$ changes were observed within a wide range of As(III) concentrations (Fig. 3f). It seemed that $\mathrm{pH}$ was only determined by the composition of LDH, as indeed a higher $\mathrm{pH}$ was observed for those ternary LDHs with a higher $\mathrm{Ca}$ content. The low leaching amount of $\mathrm{Mg}$ from $\mathrm{LDH}_{1}$ and $\mathrm{LDH}_{0.3}$ ensured the stability of the Mg-Fe LDH framework after leaching of $\mathrm{Ca}$, which favoured the adsorption of As(III) on these two LDHs.

Accordingly, the removal of As(III) was described by the following equations:

$$
\begin{gathered}
\mathrm{Mg}_{2} \mathrm{CaFe}(\mathrm{OH})_{8} \mathrm{Cl} \rightarrow \mathrm{Mg}_{2} \mathrm{Fe}(\mathrm{OH})_{6} \mathrm{Cl}+\mathrm{Ca}^{2+}+\mathrm{OH}^{-} \\
\mathrm{Ca}^{2+}+2 \mathrm{H}_{2} \mathrm{AsO}_{3}{ }^{-} \rightarrow \mathrm{Ca}\left(\mathrm{H}_{2} \mathrm{AsO}_{3}\right)_{2}
\end{gathered}
$$

$$
\mathrm{Mg}_{2} \mathrm{Fe}(\mathrm{OH})_{6} \mathrm{Cl}+\mathrm{HAsO}_{3}{ }^{-} \rightarrow \mathrm{Mg}_{2} \mathrm{Fe}(\mathrm{OH})_{6}\left(\mathrm{HAsO}_{3}\right)+\mathrm{Cl}^{-}
$$

When LDH was added to the solutions, the majority of $\mathrm{Mg}$ was retained in the LDH, supporting the framework. On the other hand, $\mathrm{Ca}$ was leached, forming an alkaline media (eqn (1)), in which $\mathrm{Ca}\left(\mathrm{H}_{2} \mathrm{AsO}_{3}\right)_{2}$ precipitated (eqn (2)), indicating the removal of $\mathrm{As}(\mathrm{III})$ by precipitation. Meanwhile, a number of $\mathrm{H}_{2} \mathrm{AsO}_{3}{ }^{-}$entered the interlayer space of the LDH, and were restrained by the LDH structure (eqn (3)), which represented an additional amount of removed As(III). Moreover, arsenate and $\mathrm{CO}_{3}{ }^{2-}$ also reacted with $\mathrm{Ca}^{2+}$, as shown in eqn (4) and (5), respectively.

$$
\begin{gathered}
\mathrm{Ca}^{2+}+\mathrm{HAsO}_{4}^{2-} \rightarrow \mathrm{CaHAsO}_{4} \\
\mathrm{Ca}^{2+}+\mathrm{CO}_{3}{ }^{2-} \rightarrow \mathrm{CaCO}_{3}
\end{gathered}
$$

In summary, these ternary LDHs, with a novel composition, present an excellent stability and significant removal capacity at the same time.

\subsection{Removal of released As(III) in a simulated paddy field system}

Although anion exchange also contributes to As(III) removal, the binding of As(III) to the LDH layers was driven by electrostatic forces, which may be compromised when exposed to a substrate with a complex composition, such as a paddy field. If this interaction was weakened, As(III) may be released into water again.

The leaching of As(III) was monitored during a 40 day period, and results are shown in Fig. 4. $\mathrm{LDH}_{1}$ and $\mathrm{LDH}_{0}$ were selected to evaluate their removal capacity in a simulated paddy field system. A control group without LDH, denoted as cg, was also monitored. For the cg, the concentration of $\mathrm{As}(\mathrm{III})$ and $\mathrm{As}(\mathrm{V})$ in
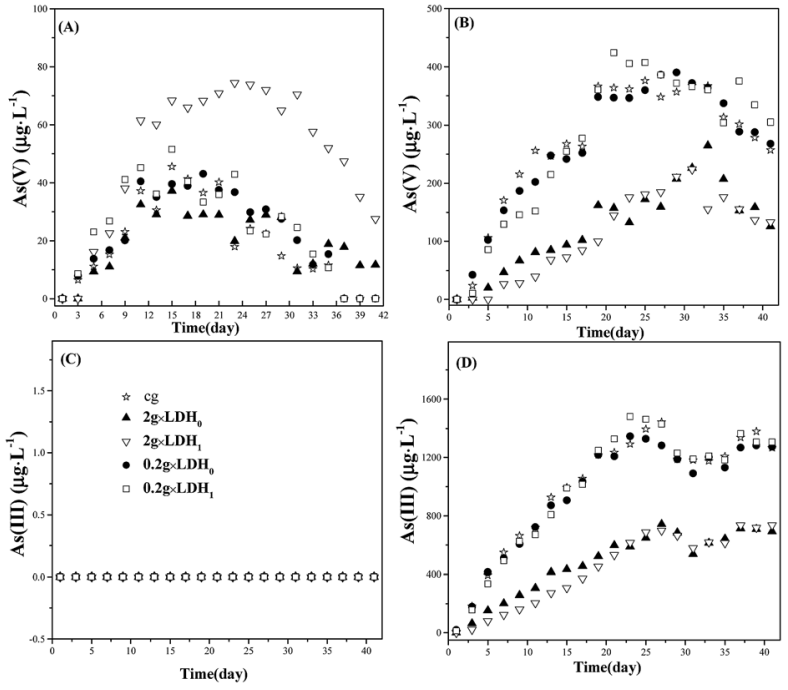

Fig. 4 Dissolution characteristic of $A s(I I)$ and $A s(V)$ in the control group (cg) and in samples with different types and dosages of $\mathrm{Mg}_{3-x} \mathrm{Ca}_{x} \mathrm{FeCl}-$ $\mathrm{LDH}$ : concentration of $\mathrm{As}(\mathrm{v})$ in (a) surface water and (b) capillary water; concentration of As(III) in (c) surface water and (d) capillary water. 
capillary water increased during the first 28 days, and then reached a stable concentration of about $1200 \mu \mathrm{g} \mathrm{L} \mathrm{L}^{-1}$ and $250 \mu \mathrm{g}$ $\mathrm{L}^{-1}$, respectively (Fig. 4B and D). As shown in Fig. 4B and D, when $2.0 \mathrm{~g}$ of $\mathrm{LDH}$ were added, the increase in As(III) concentration was clearly less pronounced. Thus, the equilibrium As(III) concentration on adding $\mathrm{LDH}_{0}$ and $\mathrm{LDH}_{1}$ was 693.2 and $635.6 \mu \mathrm{g} \mathrm{L}^{-1}$ respectively, indicating that $45.2 \%$ and $47.0 \%$ of As(III) had been removed correspondingly. This result demonstrated that the removal of As(III) on the ternary LDH was more efficient than that on the binary LDH without Ca. It also showed that, in the first 10 days, $\mathrm{LDH}_{1}$ could maintain the concentration of $\mathrm{As}(\mathrm{III})$ and $\mathrm{As}(\mathrm{v})$ at $160.88 \mu \mathrm{g} \mathrm{\textrm {L } ^ { - 1 }}$ and $39.44 \mu \mathrm{g} \mathrm{L}^{-1}$, respectively, which were $50 \%$ lower than those with $\mathrm{LDH}_{0}$. It indicated that $\mathrm{LDH}_{1}$ had a better ability to limit the release of $\operatorname{As}(\mathrm{III})$ and $\operatorname{As}(\mathrm{v})$ within the short term. Furthermore, it was found that a dosage of $0.2 \mathrm{~g}$ of $\mathrm{LDH}$ failed to prevent the release of both As(III) and As(v) into capillary water, while a dosage of $2.0 \mathrm{~g}$ was able to reduce the concentration of $\mathrm{As}(\mathrm{III})$ and $\mathrm{As}(\mathrm{V})$ to 693.2 $\mu \mathrm{g} \mathrm{L}^{-1}$ and $133 \mu \mathrm{g} \mathrm{L}{ }^{-1}$, respectively. On the other hand, the concentration of As(III) in surface water for both samples was approximately zero (Fig. 4C), as it was probably oxidized by microorganisms and $\mathrm{Mn}$ (II) released from the soil $^{24-26}$ (the content of $\mathrm{Mn}(\mathrm{II})$ was $0.05 \%$, Table $\mathrm{S} 1 \dagger$ ). This led to the concentration of $\mathrm{As}(\mathrm{V})$ in surface water escalating to around 40 $\mu \mathrm{g} \mathrm{L}^{-1}$ in the first 15 days (Fig. 4D). In the case of $2 \mathrm{~g}$ of $\mathrm{LDH}_{1}$, $\mathrm{As}(\mathrm{v})$ could be precipitated by released $\mathrm{Ca}$ from $\mathrm{LDH}$ and also being adsorbed by the LDH frame.

$\mathrm{Mg}$ and $\mathrm{Ca}$ concentrations in surface water and capillary water were monitored when $2.0 \mathrm{~g}$ of $\mathrm{LDH}$ were added to the soil samples, and results are shown in Fig. 5 (the composition of soil is shown in Table $\mathrm{S} 1 \dagger$ ). The initial $\mathrm{Mg}$ concentration was as low as to be negligible in both surface and capillary water in soil system (Fig. 5a and b). When the $\mathrm{LDH}$ was added, the $\mathrm{Mg}$ concentration in both surface water was increased, which was attributed to the $\mathrm{Mg}$ leaching from $\mathrm{LDH}$. The similar situation was observed in the capillary water. The equilibrium concentration of $\mathrm{Mg}$ in surface water and capillary water were approximately 30 and $120 \mathrm{mg} \mathrm{L}^{-1}$, respectively, suggesting that
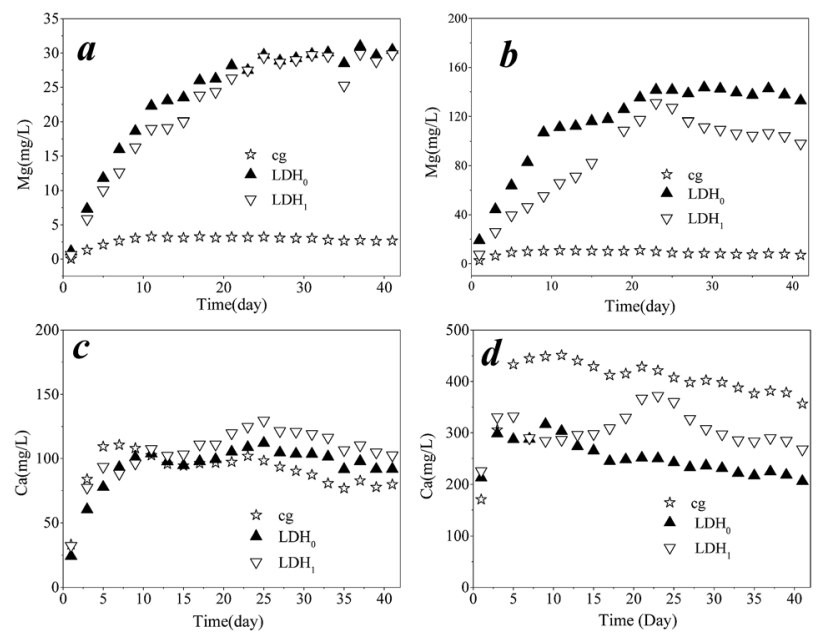

Fig. 5 Mg concentration in (a) surface water and (b) capillary water; Ca concentration in (c) surface water and (d) capillary water.

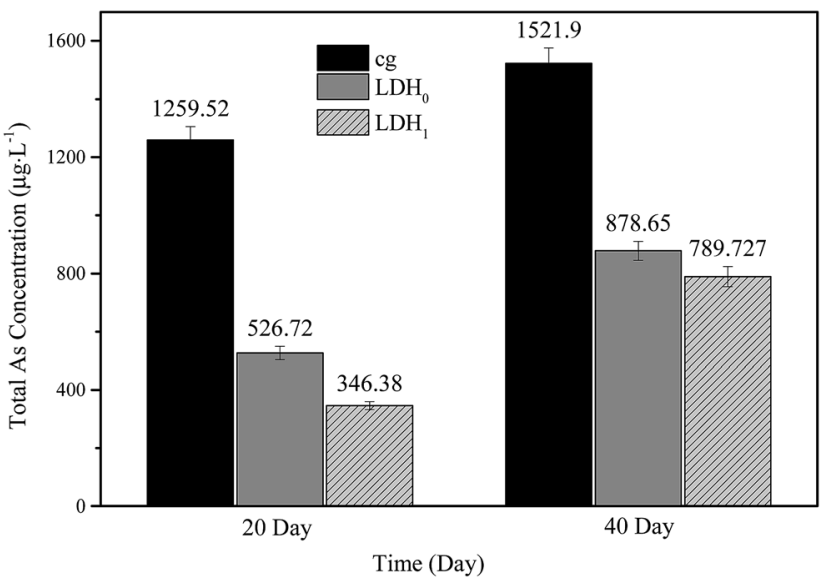

Fig. 6 Total As concentration for the control group, $\mathrm{LDH}_{0}$ and $\mathrm{LDH}_{1}$.

the majority of $\mathrm{Mg}$ was still retained within the $\mathrm{LDH}$ matrix. Meanwhile, the Ca concentration in surface water increased during the first 10 days and remained constant thereafter, at about $100 \mathrm{mg} \mathrm{L}^{-1}$, irrespective of whether $\mathrm{LDH}$ was added or not (Fig. 5c). However, the Ca concentration in capillary water when adding $\mathrm{LDH}_{0}$ and $\mathrm{LDH}_{1}$ was clearly lower than in the cg (Fig. 5d), indicating the participation of $\mathrm{Ca}$ in As(III) removal. However, the removal amount of As(III) was not as high as the theoretical value in the hypothesis that all As(III) was precipitated with $\mathrm{Ca}$ in capillary water. This was attributed to the consuming of $\mathrm{Ca}$ in the precipitation of $\mathrm{As}(\mathrm{v})$ as the decrease in the total concentration of As. Furthermore, as shown in Fig. 6, for the control sample, the concentration of total As was $1295 \mu \mathrm{g}$ $\mathrm{L}^{-1}$ after remediation for 20 days and increased to $1521 \mu \mathrm{g} \mathrm{L}^{-1}$ after 40 days. By contrast, both $\mathrm{LDH}_{0}$ and $\mathrm{LDH}_{1}$ inhibited the release of As such that a total As concentration of 526 and 346 $\mu \mathrm{g} \mathrm{L^{-1 }}$ was found after 20 days, respectively. Thus, at lower As concentrations, $\mathrm{LDH}_{1}$ showed a better performance for As immobilization than $\mathrm{LDH}_{0}$. However, after 40 days, an increase in the As concentration was also observed for the soil samples treated with $\mathrm{LDH}$ addition. The lower concentration of As in capillary water in the $\mathrm{cg}$ indicated the immobilization by LDH. In addition, a relatively low increase in $\mathrm{pH}$ was observed when $\mathrm{LDH}$ was added to the soil (Fig. S2 $\dagger$ ). Therefore, it was concluded that the ternary LDH could be a promising material for As immobilization from paddy soils.

\section{Conclusions}

A ternary LDH with enhanced removal capacity for As(III) has been successfully applied in a paddy field system. This environmentally friendly material has demonstrated an outstanding chemical stability within aqueous systems owing to the $\mathrm{Mg}$ dominant matrix, and an efficient removal via precipitation with $\mathrm{Ca}^{2+}$ ions released from the LDH matrix and interlayer anion exchange. The efficiency of the synthesized LDHs in paddy field remediation was also verified, and approximately a $47 \%$ of As(III) was removed, with a low concentration of total As of $346 \mu \mathrm{g} \mathrm{L}^{-1}$ in capillary water. Additionally, total As was immobilized more efficiently on ternary LDHs than on the 
binary $\mathrm{Mg}-\mathrm{Fe} \mathrm{LDH}$, indicating that the ternary $\mathrm{MgCaFe} \mathrm{LDH}$ is a promising material for remediation of As(III)-polluted sites.

\section{Acknowledgements}

This project was supported by the National Nature Science Foundation of China (no. 51174132, no. 21207086, no. 41402311 and no. 20877053), and the Shanghai Municipal Education Commission Innovation project (15ZZ051). We also appreciate the technical support from Instrumental Analysis \& Research Center of Shanghai University.

\section{References}

1 M. Gil-Díaz, S. Diez-Pascual, A. González, J. Alonso, E. Rodríguez-Valdés, J. R. Gallego and M. C. Lobo, Chemosphere, 2016, 149, 137-145.

2 D. Ociński, I. Jacukowicz-Sobala, P. Mazur, J. Raczyk and E. Kociołek-Balawejder, Chem. Eng. J., 2016, 294, 210-221.

3 C. M. Babu, R. Vinodh, B. Sundaravel, A. Abidov, M. P. Mei, S. C. Wang and H. T. Jang, J. Taiwan Inst. Chem. Eng., 2016, 62, 199-208.

4 B. Lan, Y. Wang, X. Wang, X. Zhou, Y. Kang and L. Li, Chem. Eng. J., 2016, 292, 389-397.

5 M. T. Olguín and S. Deng, J. Hazard. Mater., 2015, 302, 341-350.

6 D. Ghosh and A. Gupta, Resour., Conserv. Recycl., 2012, 61, 118-124.

7 X. J. Gong, W. G. Li, D. Y. Zhang, W. B. Fan and X. R. Zhang, Int. Biodeterior. Biodegrad., 2015, 102, 256-264.

8 S. Paikaray and M. J. Hendry, Appl. Clay Sci., 2013, 77-78, 33-39.

9 M. Martínez-Cabanas, M. López-García, J. L. Barriada, R. Herrero and M. E. S. D. Vicente, Chem. Eng. J., 2016, 301, 83-91.

10 A. Sigdel, J. Park, H. Kwak and P. K. Park, J. Ind. Eng. Chem., 2016, 35, 277-286.
11 S. Matsumoto, J. Kasuga, T. Makino and T. Arao, Environ. Exp. Bot., 2016, 125, 42-51.

12 M. B. Baskan and A. Pala, J. Hazard. Mater., 2009, 166, 796801.

13 K. V. Snyder, T. M. Webster, G. Upadhyaya, K. F. Hayes and L. Raskin, J. Environ. Manage., 2016, 171, 21-28.

14 E. M. Farrow, J. Wang, J. G. Burken, H. Shi, W. Yan, J. Yang, B. Hua and B. Deng, Ecotoxicol. Environ. Saf., 2015, 118, 5561.

15 P. S. Braterman, Z. P. Xu and F. Yarberry, Layered double hydroxides (LDHs), in Handbook of Layered Materials, ed. S. M. Auerbach, K. A. Carrado and P. K. Dutta, Marcel Dekker, New York, 1st edn, 2004, ch. 8, p. 373.

16 Z. Gu, J. J. Atherton and Z. P. Xu, ChemInform, 2015, 51, 3024-3036.

17 J. Zhou, Z. P. Xu, S. Qiao, Q. Liu, Y. Xu and G. Qian, J. Hazard. Mater., 2011, 189, 586-594.

18 Y. Xu, Y. Dai, J. Zhou, Z. P. Xu, G. Qian and G. Q. M. Lu, J. Mater. Chem., 2010, 20, 4684-4691.

19 G. Carja, S. Ratoi, G. Ciobanu and I. Balasanian, Desalination, 2008, 223, 243-248.

20 M. Stachowicz, T. Hiemstra and W. H. V. Riemsdijk, J. Colloid Interface Sci., 2008, 320, 395-396.

21 K. Grover, S. Komarneni and H. Katsuki, Water Res., 2009, 43, 3884-3890.

22 J. Zhou, Z. P. Xu, S. Qiao, Q. Liu, Y. Xu and G. Qian, J. Hazard. Mater., 2011, 189, 586-594.

23 CRC Handbook of Chemistry and Physics, ed. D. R. Lide, Boca Raton, FL, 2007.

24 R. Seith and M. Jekel, Vom Wasser, 1997, 89, 283-296.

25 W. Driehaus, R. Seith and M. Jekel, Water Res. , 1995, 29, 297305.

26 B. Hambsch, B. Raue and H. Brauch, Acta Hydrochim. Hydrobiol., 1995, 23, 166-172. 